\title{
Características do amido do grão de milho processado por reconstituição e moagem para uso na alimentação de ruminantes
}

\author{
Characteristics of the starch of corn grain processed by reconstitution and grinding for \\ use in ruminant feed
}

\author{
SILVA, Cássio José da ${ }^{1 *}$; PEREIRA, José Carlos ${ }^{2}$; OLIVEIRA, Tadeu Silva ${ }^{3}$; \\ CABRAL FILHO, Sérgio Lúcio Salomon ${ }^{1}$; MENDES, Clayton Quirino ${ }^{1}$; LEITE, \\ Gilberto Gonçalves ${ }^{1}$; DIOGO, José Mauro da Silva ${ }^{1}$
}

\author{
${ }^{1}$ Universidade de Brasília, Faculdade de Agronomia e Medicina Veterinária, Brasília, Distrito Federal, Brasil. \\ ${ }^{2}$ Universidade Federal de Viçosa, Departamento de Zootecnia, Minas Gerais, Brasil. \\ ${ }^{3}$ Universidade Estadual do Norte Fluminense Darcy Ribeiro, Laboratório de Zootecnia e Nutrição Animal. \\ Campos dos Goytacazes, Rio de Janeiro, Brasil. \\ *Endereço para correspondência: cassiojs@unb.br
}

\section{RESUMO}

Objetivou-se com este trabalho avaliar a reconstituição da umidade associada à moagem grosseira do grão de milho sobre as características macroscópicas e microscópicas dos grãos. O experimento foi realizado no Laboratório de Nutrição animal do Departamento de Zootecnia da Universidade Federal de Viçosa. Foram utilizadas as seguintes combinações de processamento do milho: milho com reconstituição da umidade depois da moagem a $5 \mathrm{~mm}$ (MRD); milho com reconstituição da umidade antes da moagem a 5 mm (MRA) e milho moído a $1 \mathrm{~mm}$ (MMF). Foram realizados os ensaios de avaliação da atividade da enzima $\alpha$-amilase sobre o amido dos grãos, microscopia eletrônica de varredura para os grãos de milho processados e avaliação da granulometria. O MRA apresentou maior número de partículas com tamanho acima de $1,19 \mathrm{~mm}$ devido ao fato de a reconstituição ocorrer antes do processo de moagem, o que favorece a liberação da maior parte do pericarpo aderido ao grão de milho. Microscopicamente, os grânulos de amido não apresentaram variações na estrutura básica padrão sendo que algumas alterações observadas nas imagens de microscopia eletrônica de varredura foram devidas à preparação das amostras para visualização. A taxa de liberação de amido pela a ação da enzima $\alpha$-amilase (Novozymes, Termamyl 2x) seguiu mesmo padrão para os três tipos de processamento.

Palavras-chave: amido, processamento de grãos, reconstituição da umidade

\section{SAMMURY}

The aim of this study was to evaluate the effects of moisture reconstitution associated with coarse milling of corn grain on macroscopic and microscopic grain characteristics. The experiment was conducted at the Laboratory of Animal Nutrition, Department of Animal Science, Federal University of Viçosa. The following corn processing combinations were tested: corn reconstituted after being milled to 5 $\mathrm{mm}$ (CRA); corn reconstituted before being milled to $5 \mathrm{~mm}$ (CRB); and corn milled to $1 \mathrm{~mm}$ (CGF). Evaluation assays of $\alpha$-amylase enzyme activity on the grain's starch, scanning electron microscopy for processed kernels, and particlesize analysis were undertaken. The highest number of particles larger than $1.19 \mathrm{~mm}$ was found in CRB, because reconstitution occurred prior to the milling process, which facilitates the release of the largest part of the pericarp adherent to the corn grain. Microscopically, the starch granules did not display variations in their basic standard structure, and some alterations observed in the scanning electron microscopy images were due to the preparation of samples for visualization. There was no effect of grain processing on the rates of starch released by the action of the $\alpha$-amylase enzyme (Novozymes, Termamyl 2x).

Keywords: grain processing, moisture reconstitution, starch 


\section{INTRODUÇÃO}

O pericarpo e a matriz protéica que envolvem os grânulos de amido no endosperma vítreo do milho duro, tipo mais comum no Brasil, consistem nas duas principais barreiras à colonização e a ação enzimática microbiana no rúmen, sendo que a maioria dos processamentos tem como objetivo eliminar essas barreiras primárias (KOTARSKI et al., 1992). Assim, o processamento do milho serve para expor os grânulos de amido à digestão (BEAUCHEMIN et al., 1994), formando fissuras, quebrando, ou expandindo o amido.

Outro ponto importante associado ao processamento do milho é que este tem participado em média com $75 \%$ da composição total da ração de bovinos, sendo normalmente moído a $1 \mathrm{~mm}$. Estima-se que $3 \%$ de toda a energia consumida no mundo seja gasta para a redução do tamanho de partículas por meio da moagem, incluindo minérios e insumos para as indústrias química, farmacêutica e alimentícia (TAVARES, 2001). Desse modo, apesar de a moagem objetivar uma mistura homogênea dos ingredientes, facilitar o processo de digestão e melhorar a qualidade final dos produtos, também contribui para aumentar o custo de produção das rações. Healy et al. (1994), em um estudo para avaliar a influência da redução do tamanho da partícula no rendimento de moagem e no consumo de energia, demonstraram que a energia elétrica gasta para a moagem do grão de milho a $900 \mathrm{~mm}$ foi de $5,3 \mathrm{kWh} / \mathrm{ton}$, com uma produção de 1,76 ton/h. Após a redução do tamanho da partícula para $300 \mathrm{~mm}$ ocorreu aumento no consumo de energia elétrica para $24,5 \mathrm{kWh} /$ ton e uma redução na produção de ração para 0,65 ton $/ \mathrm{h}$. Esses resultados demonstram a necessidade de aperfeiçoar a moagem de forma a maximizar o aproveitamento do alimento e aumentar a eficiência no uso da energia. Assim a reconstituição de grãos de milho moídos grosseiramente, pode auxiliar no processo de digestão e ao mesmo tempo causar reduções significativas de consumo de energia para moagem dos grãos.

Considerando que a umidade pode facilitar a ação enzimática microbiana e aumentar o aproveitamento do amido no rúmen, objetivou-se com este estudo avaliar a reconstituição associada a moagem grosseira dos grãos de milho sobre as características macroscópicas e microscópicas dos grãos, bem como a disponibilidade do amido a ação enzimática.

\section{MATERIAL E MÉTODOS}

Os ensaios foram realizados no Laboratório de Nutrição animal do Departamento de Zootecnia da Universidade Federal de Viçosa. Os tratamentos foram compostos pela combinação de duas diferentes formas de processamento dos grãos de milho tipo "duro", a reconstituição da umidade e a moagem. Os tratamentos foram os seguintes: MMF - Milho moído fino (1mm); MRA - Milho com reconstituição da umidade antes da moagem a $5 \mathrm{~mm}$ e MRD - Milho com reconstituição da umidade depois da moagem a $5 \mathrm{~mm}$.

Nos tratamentos envolvendo a reconstituição, objetivou-se elevar o teor de umidade a $33 \%$ e os procedimentos foram baseados na a equação, adaptada de Ferreira (1983):

$$
\Delta \mathrm{H}_{2} \mathrm{O}=\left[\mathrm{MU} * \frac{(\mathrm{Uf}-\mathrm{Ui})}{100-\mathrm{Ui}}\right] / \rho
$$

onde: $\Delta \mathrm{H}_{2} \mathrm{O}=$ Volume de água a ser adicionado (litros); $\mathrm{MU}=$ Massa do produto úmido $(\mathrm{kg})$; $\mathrm{Uf}=$ Umidade final ( $\%$ base úmida); $\mathrm{Ui}=$ Umidade inicial $(\%$ base úmida); $p=$ Massa específica da água $(\mathrm{kg} / \mathrm{L})$. 
Rev. Bras. Saúde Prod. Anim., Salvador, v.17, n.4, p.710-718 out./dez., 2016 http://www.rbspa.ufba.br ISSN 15199940

Foram utilizados aproximadamente $5 \mathrm{~kg}$ de milho com umidade inicial de 10,2\% em cada tratamento, com três repetições. No tratamento MRD, o milho foi inicialmente moído a $5 \mathrm{~mm}$, em seguida foi adicionado 1,27 litro de água a temperatura ambiente. Este material foi mantido por um período de descanso de 24 horas. Já no MRA, foi adicionado 1,27 litro água também a temperatura ambiente nos grãos inteiros com período de descanso de 24 horas e em seguida moídos a $5 \mathrm{~mm}$.

A determinação do perfil granulométrico das partículas do milho processado foi realizada com o uso de peneiras padronizadas (Tab. 1), além de bandeja inferior com a finalidade de recolher as partículas menores do que $0,297 \mathrm{~mm}$.

Tabela 1. Relação de malha, abertura e espessura dos fios das peneiras padronizadas pela norma ISO - 3310/1

\begin{tabular}{ccccc}
\hline Malha & Abertura $(\mathrm{mm})$ & Tolerância & Diâmetro do fio & Tolerância \\
\hline 4 & 4,76 & 4,60 a 4,90 & $1,6 \mathrm{~mm}$ & 1,3 a 1,9 \\
8 & 2,38 & 2,28 a 2,44 & $1,0 \mathrm{~mm}$ & 0,85 a 1,15 \\
16 & 1,19 & 1,14 a 1,22 & $0,63 \mathrm{~mm}$ & 0,54 a 0,72 \\
18 & 1,0 & 0,97 a 1,03 & $0,56 \mathrm{~mm}$ & 0,48 a 0,64 \\
25 & 0,71 & 0,685 a 0,735 & $0,45 \mathrm{~mm}$ & 0,38 a 0,52 \\
50 & 0,297 & 0,288 a 0,312 & $0,20 \mathrm{~mm}$ & 0,17 a 0,23 \\
\hline
\end{tabular}

As amostras de MRD e MRA foram pesadas em porções de $140 \mathrm{~g}$ e distribuídas nas peneiras, essas foram movimentadas por agitador mecânico modelo Produtest ${ }^{\circledR}$ em intensidade máxima, durante um minuto, de acordo com o descrito por Felisberto (2011). Ao final da agitação o material retido em cada peneira foi pesado em balança digital com duas casas decimais. O MMF não foi submetido ao peneiramento, pois não passou por processo de reconstituição da umidade.

$\mathrm{O}$ peso do material retido em cada peneira foi então expresso como percentual do peso total da amostra avaliada, enquanto que o peso de material considerado fisicamente efetivo foi o percentual do peso total retido em peneiras com abertura maior que $1,19 \mathrm{~mm}$.

A técnica de microscopia eletrônica de varredura foi utilizada para estudar as características de forma, tamanho e distribuição dos grânulos de amido. As amostras de MRA, MRD e MMF foram secas em estufa a $105^{\circ} \mathrm{C}$ e preparadas para observação em microscopia eletrônica de varredura. Devido ao fato de as amostras já estarem secas não foi necessária a fixação com glutaraldeído e paraformaldeído, em tampão fosfato (KARNOVSKY, 1965), assim, as amostras foram diretamente cobertas com ouro em metalizador (modelo FDU 010, Bal-Tec, Balzers, Liechtenstein). A captura de imagens foi realizada em um microscópio eletrônico de varredura (Zeiss, LEO $1430 \mathrm{VP}$ ), localizado no Núcleo de Microscopia e Microanálise da Universidade Federal de Viçosa.

Já para avaliação da combinação dos processamentos sobre a velocidade de digestão pela enzima $\alpha$-amilase, foi realizado um ensaio seguindo o protocolo de determinação de amido conforme a metodologia proposta por Bach Knudsen (1997), com modificações no tempo de atuação da $\alpha$-amilase.

As determinações de amido no MMF, MRA e MRD foram realizadas colocando-se em tubos de ensaio de 40 $\mathrm{mL}$, aproximadamente $0,20 \mathrm{~g}$ de amostra. 
Rev. Bras. Saúde Prod. Anim., Salvador, v.17, n.4, p.710-718 out./dez., 2016 http://www.rbspa.ufba.br ISSN 15199940

Nos tubos previamente pesados foram adicionados $30 \mathrm{~mL}$ de solução tampão de acetato de sódio $(\mathrm{pH}=5,00 \pm 0,05$ a 0,1 mol L $\mathrm{L}^{-1}$ ) e adicionada $50 \mu \mathrm{L}$ da enzima $\alpha$ amilase (Novozymes, Termamyl 2x). Todos os tubos de ensaio foram homogeneizados em agitador e posteriormente, incubados em banhomaria a $100^{\circ} \mathrm{C}$ por $0,15,30,45$ e 60 minutos, com homogeneização de todos os tubos em cada tempo de retirada. A cada retirada do banho-maria era esperado que os tubos atingissem a temperatura ambiente. A partir daí foi adicionado $1 \mathrm{~mL}$ da solução contendo 100 unidades da enzima amiloglicosidade por mL (Megazyme, E-AMGDF).

Os tubos foram novamente agitados $\mathrm{e}$ colocados em banho-maria a $60^{\circ} \mathrm{C}$ por 2 horas, sendo agitados após 1 hora de incubação. Após as 2 horas, os tubos foram colocados na bancada até atingirem temperatura ambiente. Posteriormente os mesmos foram pesados (para correção do volume) e a solução foi transferida para tubos de $50 \mathrm{~mL}$ e centrifugada a $2,060 \mathrm{~g}$ por 10 minutos a uma temperatura de $10^{\circ} \mathrm{C}$. Em seguida utilizou-se $10 \mu \mathrm{L}$ de da solução centrifugada de cada tubo centrifugado para reagir com $1 \mathrm{~mL}$ de solução estável de um kit comercial de glicose GOD PAP (Laborlab, 06400), numa diluição de 1:100. Após 15 minutos de reação a $23^{\circ} \mathrm{C}$, foi realizada a leitura em espectrofotômetro (Shimadzu, UV 1601 PC) a $505 \mathrm{~nm}$. O conteúdo de amido foi calculado multiplicando-se o resultado final de glicose por 0,9 (para converter glicose livre em amido), e apresentado como porcentagem da matéria seca. Para cada reação foi feita uma curva padrão com solução de glicose padrão. Para cada ensaio foram utilizadas duas amostras padrões (amido puro e fubá de milho) e um branco. Os dados obtidos em cada ensaio foram analisados descritivamente.

\section{RESULTADOS E DISCUSSÃO}

A maior parte do material fluiu pela peneira de $4,76 \mathrm{~mm}$ indicando que o processo de moagem a $5 \mathrm{~mm}$ foi eficiente. No entanto observa-se também que independentemente do tipo de processamento efetuado, aproximadamente $50 \%$ das partículas foram retidas em peneira de $1,19 \mathrm{~mm}$, tamanho este considerado crítico para a elegibilidade de escape do compartimento rúmen-retículo (PEREIRA et al., 2002). $\mathrm{O}$ tamanho de partícula teve influência sobre o porcentual retido nas peneiras de $1,19 \mathrm{~mm}$, sendo em média $54,35 \%$ para o milho processado a $5 \mathrm{~mm}$.

Tabela 2. Perfil granulométrico das partículas do milho processado expresso em percentual médio acumulado nas peneiras

\begin{tabular}{lcc}
\hline Abertura da peneira $(\mathrm{mm})$ & MRD & MRA \\
\hline $4,76 \mathrm{~mm}$ & 0,97 & 0,44 \\
$2,38 \mathrm{~mm}$ & 33,21 & 38,47 \\
$1,19 \mathrm{~mm}$ & 50,83 & 57,87 \\
$1,00 \mathrm{~mm}$ & 71,23 & 85,01 \\
$0,71 \mathrm{~mm}$ & 79,86 & 93,06 \\
$0,297 \mathrm{~mm}$ & 91,18 & 98,48 \\
\hline Parâmetros & MRD & MRA \\
\hline Desvio padrão geométrico & 3,26 & 3,72 \\
Diâmetro geométrico médio & 1,19 & 1,33 \\
\hline MRA = Milho reconstituído antes da moagem a $5 \mathrm{~mm} ;$ MRD = Milho reconstituído depois da moagem a \\
5 mm.
\end{tabular}


No caso de dietas com alta concentração de energia e/ou secas, contendo volumosos com fibra de baixa qualidade como feno de algumas forrageiras ou bagaço de cana, pode ocorrer segregação da dieta com a moagem fina. Já com a moagem mais grosseira, com mais da metade das partículas acima de 1,19mm pode ocorrer maior homogeneização da ração e aumento da retenção do milho no rúmen devido à redução na taxa de passagem, além de reduzir a velocidade da fermentação devido ao maior tamanho de partícula, em relação à moagem fina. Embora uma parte possa escapar e ser eliminada via fezes, ocorre maior prevenção da acidose ruminal subclínica.

Pode ser verificado na Figura 1 que o MRA apresentou maior porcentagem $(57,87 \%)$ de partículas com tamanho maior que $1,19 \mathrm{~mm}$, contra $(50,83 \%)$ do MRD. Isso ocorreu devido a grande mudança física que acontece durante $\mathrm{o}$ processamento, em que no MRA, a maior parte do pericarpo se desprende do endosperma durante $\mathrm{o}$ processo de moagem. Já no MRD o pericarpo continua aderido as partículas de milho durante o processo, consequentemente este é reduzido a partículas menores, o que foi comprovado pelo menor diametro geométrico médio (DGM) apresentado pelas partículas no processamento MRA. Jobim (1996) afirmou que os grãos de milho, mesmo quando triturados ou parcialmente quebrados, são protegidos pelo pericarpo, que é aprincipal barreira primária a colonização microbiana e ação enzimática no rúmen. Assim, a maior porcentagem do MRA retido na peneira de $1,19 \mathrm{~mm}$ se deve a quantidade de partículas de pericarpo retidaneste diâmetro de furo, que se descolaram do endosperma devido a hidratação que ocorreu durante $\mathrm{o}$ processo de reconstituição e assim não foram quebradas durante a moagem.

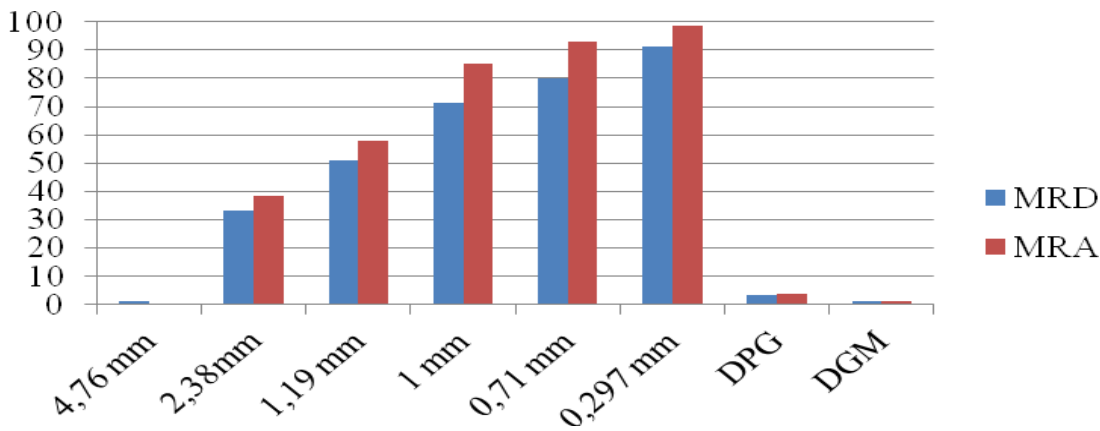

Figura 1. Porcentual de partículas de milho reconstituído antes da moagem a $5 \mathrm{~mm}$ (MRA) e milho reconstituído depois da moagem a $5 \mathrm{~mm}$ (MRD) retidos nas peneiras, diâmetro geométrico médio (DGM) e desvio padrão geométrico (DPG)

O efeito da reconstituição da umidade na proteção pelo pericarpo pode ser observado na Figura 2, onde no milho reconstituído por $24 \mathrm{~h}$, seguido de moagem grosseira a $5 \mathrm{~mm}$, ocorreu a liberação da maior partedo
pericarpo.Por outro lado, quando os grãos de milho foram inicialmente moídos grosseiramente e em seguida passaram pelo processo de reconstituição (MRD), não ocorreu a liberação do pericarpo. 


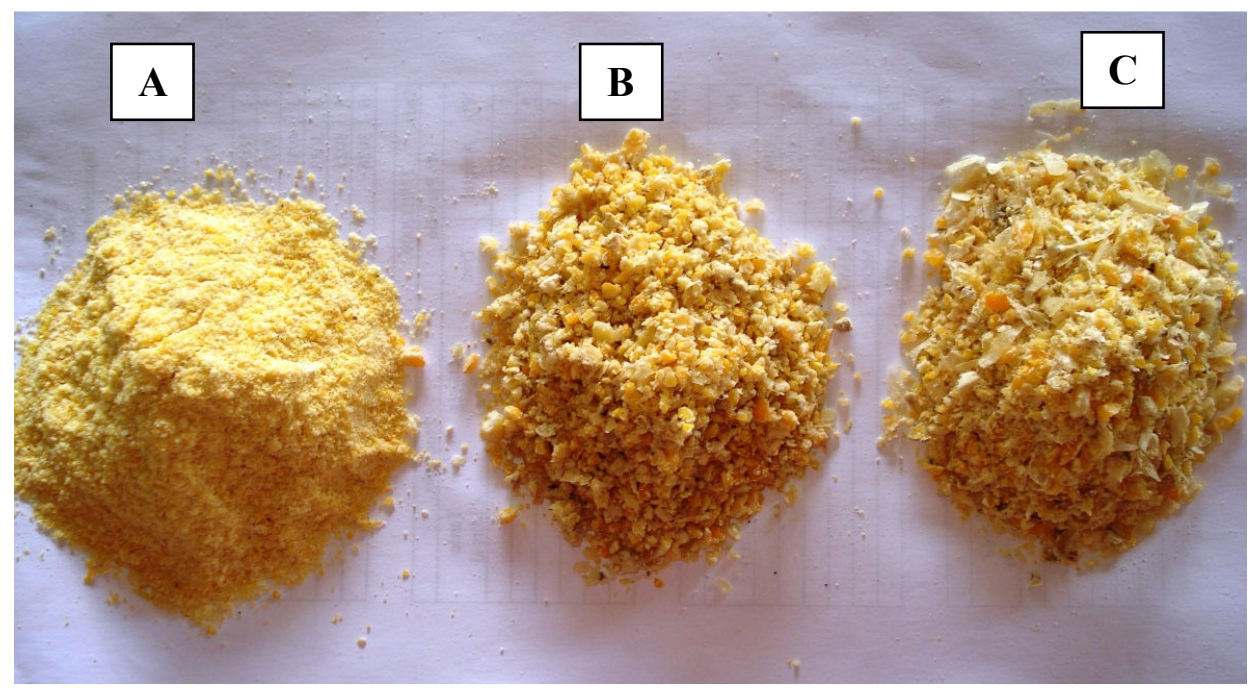

Figura 2. A - Milho moído fino (1mm); B - Milho reconstituído depois da moagem a $5 \mathrm{~mm}$ e $\mathrm{C}$ - Milho reconstituído antes da moagem a $5 \mathrm{~mm}$

Foi observada ainda, uma pequena elevação da temperatura das partículas de milho durante o período de descanso de 24h no processamento MRD, provavelmente devido a um início de fermentação causado pelos microrganismos presentes naturalmente no milho.

Com a elevação da temperatura, pode ocorrer uma liberação do amido preso a matriz proteica, cujo processo é denominado gelatinização. Embora a gelatinização do amido pelo aquecimento possa favorecer a digestibilidade do milho em ruminantes, é pouco provável que isso ocorra com a moagem seguida de reconstituição com água a temperatura ambiente. Segundo Colonna et al. (1995), a gelatinização do amido do milho começa à temperatura de $62^{\circ} \mathrm{C}$ e termina em $72^{\circ} \mathrm{C}$, temperaturas que não são atingidas durante a ensilagem $\mathrm{e}$ armazenagem para reconstituição.

O amido do milho apresentou uma mistura de grânulos de diversos tamanhos predominantemente arredondados. O tamanho e a forma dos grânulos de amido se apresentaram em acordo com as características previamente conhecidas para o milho.

Nota-se que nos tratamentos envolvendo a reconstituição (Figura 3, A, B, C e G, H, I), os grânulos se encontram mais espaçados e com a superfície mais irregular, provavelmente devido ao espaço ocupado pela água antes do processo de secagem para preparação das amostras.

Podem ser observadas irregularidades de superfície e fissuras sobre os grânulos corrigidos pela seta branca na Figura 2, F. A superfície dos grânulos se mostra plana e sem traços marcantes, exceto por algumas estrias em alguns grânulos (seta preta na Figura 3, letra I), seguindo as características dos modelos propostos por Oates (1997), descritas como uma "bola de bilhar peluda", em que a superfície do grânulo de amido não é lisa, mas com estrias projetadas para fora. Os tratamentos envolvendo a reconstituição não causaram alterações que possam aumentar o acesso dos microrganismos ao amido no interior do grânulo, como por exemplo, o rompimento da matriz proteica que envolve os grânulos de amido. 


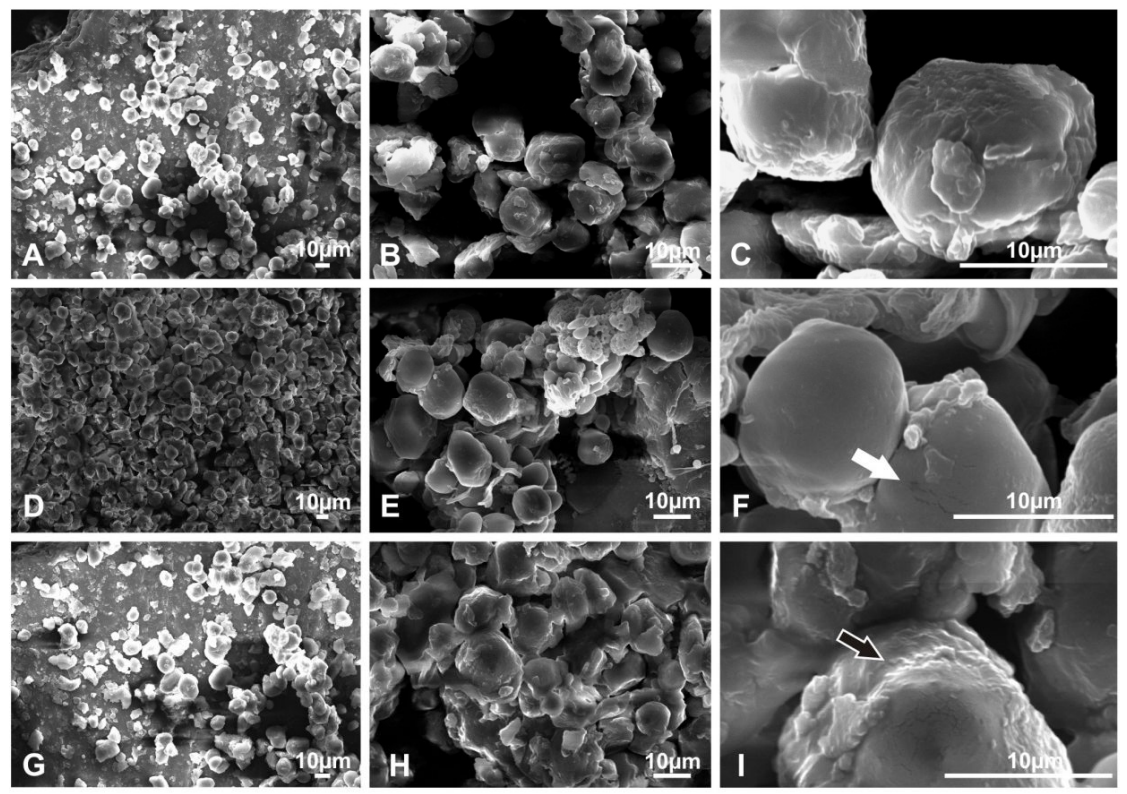

Figura 3. Fotomicrografia eletrônica do milho processado. A, B e C Milho reconstituído antes da moagem $(5 \mathrm{~mm})$; D, E e F Milho moído fino $(1 \mathrm{~mm})$ e $\mathrm{G}, \mathrm{H}$ e I - Milho reconstituído depois da moagem $(5 \mathrm{~mm})$

A organização anatômica do grânulo parece não permitir a entrada de água a temperatura ambiente. Este impedimento é devido à disposição paralela das macromoléculas, que são estabilizadas por ligações de hidrogênio (Denardin \& Silva, 2008). Provavelmente após a secagem o grânulo encolhe, até voltar ao estado anidro causado uma contração completa, originando os espaços observados e as fissuras nos grânulos nos tratamentos envolvendo a reconstituição. A quantidade de amido medido ao longo do tempo foi muito semelhante para o milho reconstituído (MRA e MRD) e o milho não reconstituído (MMF). Os dados apresentados por meio das linhas de tendência confirmam o fato de que o amido é geralmente insolúvel em água à temperatura ambiente e assim pouca ou nenhuma alteração na velocidade de liberação pela enzima $\alpha$-amilase ocorreu nesse ensaio (Figura 4).

Grânulos de amido parecem ser bastante resistentes à penetração por água $\mathrm{e}$ enzimas hidrolíticas, pois de acordo com a Figura 3, a umidade não acelera a ação da enzima $\alpha$-amilase. Segundo Denardin \& Silva (2008), estão presentes pontes de hidrogênio dentro de uma mesma molécula de amilose e com outras moléculas vizinhas. No entanto, estas ligações podem tornar-se fracas quando a temperatura da suspensão é elevada. Porém isso não ocorreu nos processamentos utilizados neste trabalho, assim não se verificou grandes variações na quantidade de amido liberado ao longo do tempo.

Quando o amido é aquecido em meio aquoso, as pontes de hidrogênio enfraquecem, a água é absorvida, e os grânulos de amido incham. Este processo é normalmente chamado de gelatinização, porque a solução formada tem uma consistência gelatinosa e altamente viscosa. Segundo French (1984), a porosidade dos grânulos de amido à água e a pequenas moléculas solúveis ocorre devido à expansão reversível das regiões amorfas, que 
Rev. Bras. Saúde Prod. Anim., Salvador, v.17, n.4, p.710-718 out./dez., 2016 http://www.rbspa.ufba.br

penetram por todo o grânulo durante a hidratação, formando uma fase contínua de gel. No entanto, a entrada de enzimas hidrolizantes e outras moléculas grandes para o interior dos grânulos é restrita e somente possível através de poros ou canais. No entanto, como dito anteriormente, não ocorreu aumento da temperatura do milho para que ocorresse a gelatinização.

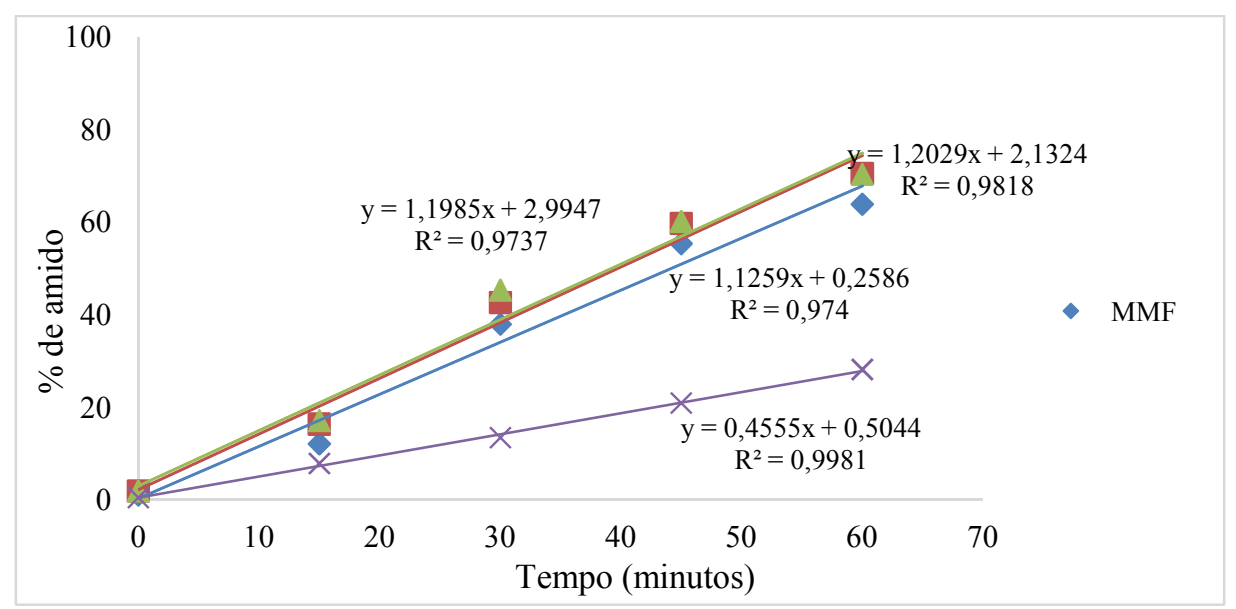

Figura 4. \% de amido liberado pela enzima $\alpha$-amilase em função dos tipos de processamento. $\mathrm{MMF}=$ Milho Moído Fino $(1 \mathrm{~mm})$; MRA = Milho reconstituído antes da moagem a $5 \mathrm{~mm}$; MRD $=$ Milho reconstituído depois da moagem a $5 \mathrm{~mm}$ e Silagem de Milho

Estudos de microscopia eletrônica sugerem orifícios com diâmetros entre 0,1 e $0,3 \mu \mathrm{m}$, enquanto canais interiores teriam entre 0,07 e $0,1 \mu \mathrm{m}$ (ELIASSON, 1996; ELIASSON, 2004). Porém, mais estudos devem ser realizados para comprovar a existência desses poros e canais em todas as fontes de amido, pois neste trabalho não foi visualizado nenhuma evidência de poros na superfície dos grânulos. Lan et al. (2008) também não verificaram a existência dos mesmos.

A reconstituição feita antes da moagem a $5 \mathrm{~mm}$ promove a liberação da maior parte do pericarpo aderido ao grão de milho. Microscopicamente, a reconstituição não altera a estrutura dos grânulos de amido sendo que algumas alterações podem ser devido à preparação das amostras para visualização. A quantidade de amido liberado pela ação enzimática também não é afetada quando o grão de milho é reconstituído antes ou depois da moagem.

\section{REFERÊNCIAS}

BACH KNUDSEN, K.E. Carbohydrate and lignin contents of plant materials used in animal feeding. Animal Feed Science and Technology, v. 67, p.319338, 1997.

BEAUCHEMIN, K.A.; McALLISTER, T.A.; DONG, Y. et al. Effects of mastication on digestion of whole cereal grains by cattle. Journal of Animal Science, v.72, n.2, p.236-246, 1994. 
Rev. Bras. Saúde Prod. Anim., Salvador, v.17, n.4, p.710-718 out./dez., 2016 http://www.rbspa.ufba.br ISSN 15199940

DENARDIN, C.C.; SILVA, L.P. Estrutura dos grânulos de amido e sua relação com propriedades físicoquímicas. Ciência Rural, Santa Maria. 2008.

ELIASSON, A.C. Carbohydrates in food. New York: Marcel Dekker, 1996. $664 p$.

ELIASSON, A.C. Starch in food Structure, function and applications. New York: Boca Raton, 2004. 605p.

FELISBERTO, N.R.O. Tamanho da partícula da forragem em dietas de cabras leiteiras. 2011. 120p. Tese (Doutorado em Zootecnia) Universidade Federal de Viçosa, Viçosa.

FERREIRA, W.A. Armazenamento de grãos de cereais. In: CEREDA. M.P.; SANCHES, L. (Eds). Manual de armazenamento e embalagem de produtos agropecuários. Botucatu: UNESP,1983. p. 96-128.

FRENCH, D. Organization of starch granule. In: WHISTLER, R. L.; BEMILLER, J. N.; PASCHAL, E.F. (Eds.). Starch: chemistry and Tecnology. 2.ed. London: Academic Press, 1984. p.183-247.

HEALY, B.J. et al. Optimum particle size of corn and hard and soft sorghum for nursery pigs. Journal of Animal Science, v.72, p.2227-2236, 1994.

JOBIM, C.C. Avaliação das características microbiológicas, químicas e digestibilidade das silagens de grãos úmidos e de espiga de milho. 1996. 98f. Tese (Doutorado e Zootecnia) - Faculdade de Ciências Agrárias e Veterinárias, Universidade Estadual Paulista, Jaboticabal.
KARNOVSKY, M.J. A formaldehydeglutaraldehyde fixative of high osmolality for use in electron microscopy. Jounal of Cell Biology, v.27, p.137-138, 1965.

KOTARSKI, K.K.; WANISHA, R.D.; THURN, K.K. Starch hydrolysis by the ruminal microflora. Journal of Nutrition, v.122, p.178 - 184. 1992.

LAN, H. et al. Impact of annealing on the molecular structure and physicochemical properties of normal, waxy and high amylose bread wheat starches. Food Chemistry, v.111, p.663-675, 2008.

OATES, C.G. Towards and understanding of starch granule structure and hydrolysis. Trends in Food Science \& Technology, v.8, p.375-382, 1997.

PAES, M.C.D. Aspectos físicos, químicos e tecnológicos do grão de milho. Sete Lagoas, MG: Embrapa Milho e Sorgo. 2006. (Circular Técnica).

STARK, J.R.; LYNN, A. Biochemistry of plant polysaccharides: starch granules large and small. Biochemical Society Transactions, v.20, p.7-12, 1992.

TAVARES, L.M. Um método para o cálculo da eficiência energética de moinhos industriais. Revista Matéria. Periódico científico virtual da área de materiais. 2001. Disponível em: $<$ www.materia.coppe.ufrj.br $>$. Acesso em: 1 ago. 2009.

Data de recebimento: $14 / 02 / 2016$ Data de aprovação: 30/08/2016 